\title{
Self-perceived Sleep Quality and Quantity in Adults With Asthma: Findings From the CosteAsma Study
}

\author{
Sanz de Burgoa $\mathrm{V}^{1}$, Rejas $\mathrm{J}^{2}$, Ojeda $\mathrm{P}^{3}$ on behalf of the investigators of the \\ Coste Asma study
}

\author{
'Medical Department, Pfizer S.L.U., Alcobendas, Madrid, Spain \\ ${ }^{2}$ Health Economics and Outcomes Research Department, Pfizer S.L.U., Alcobendas, Madrid, Spain \\ ${ }^{3}$ Clínica de Asma y Alergia Dres. Ojeda, Madrid, Spain
}

J Investig Allergol Clin Immunol 2016; Vol. 26(4): 256-262

doi: 10.18176/jiaci.0044

\begin{abstract}
Background and Objective: Nocturnal asthma symptoms are associated with poor sleep quality, excessive daytime sleepiness, and poor daytime functioning. The aim of this study was to describe self-perceived sleep quality and quantity in asthmatic adults in a real-world setting according to different determinants of patient health status.

Methods: A cross-sectional, observational, seasonal, multiwave survey was designed. Allergists nationwide were asked to consecutively survey adult asthmatics aged 18 to 65 years, evenly distributed by seasons and asthma severity (Global Initiative for Asthma criteria). Sleep quality and quantity were assessed using the self-administered Medical Outcomes Study (MOS) Sleep Scale. The Asthma Control Test was applied to ascertain the degree of asthma symptom control.

Results: A total of 1098 individuals (58.7\% females, 41.2 [13.6] years) were analyzed. Asthma severity was associated with poor sleep quality and quantity; patients with more severe disease scored higher on the MOS Sleep Scale $(P<.001)$ and also reported significantly fewer daily average hours of sleep (0.3-0.5 hours, $P<.001)$. Level of symptom control and asthma severity were both associated with poor sleep quality and quantity, with the following mean MOS sleep problem index scores: 25.3 (fully controlled asthma), 26.4 (controlled), 32.6 (partly controlled), and 44.6 (uncontrolled) $(P<.001)$, and 48.4 (severe asthma), 39.0 (moderate), 32.6 (mild), and 26.5 (intermittent) $(P<.001)$. Sex was significantly associated with the summary MOS sleep problem index.

Conclusions: Sleep quality and quantity was significantly associated with poor health status in asthmatic patients. Guidelines should recommend asking about nocturnal asthma symptoms and encourage clinicians to take a global sleep history. Better control of nocturnal asthma symptoms could lead to improved sleep quality and a decrease in daytime sleep-related symptoms.
\end{abstract}

Key words: Asthma. Real-world setting. Sleep quality and quantity. MOS sleep scale. Disability.

\section{Resumen}

Introducción y Objetivo: Los síntomas nocturnos de asma, están asociados con la calidad de la falta de sueño, somnolencia diurna excesiva y mal funcionamiento durante el día. El objetivo de este estudio fue describir la calidad y cantidad del sueño percibida por el paciente asmático en un emplazamiento de vida real según diferentes determinantes del estado de salud del paciente.

Métodos: Se diseñó una encuesta de corte transversal, observacional, en olas estacionales. Se les pidió a alergólogos de todo el país que realizaran una encuesta de forma consecutiva a asmáticos de 18-65 años, distribuido por estaciones y gravedad (criterios GINA). Cantidad y calidad del sueño se evaluaron utilizando la escala autoadministrada de sueño MOS-sleep scale. La escala ACT se aplicó para determinar el grado de control de síntomas asmáticos.

Resultados: Un total de 1.098 sujetos [58,7\% mujeres, 41,2 (13,6) años] se incluyeron en el análisis. La gravedad del asma se relacionó con calidad/cantidad de falta de sueño, con puntuaciones más altas en los pacientes más graves $(p<0,001)$, que tenían significativamente menos horas promedio diarias de sueño: $0,3-0,5$ horas $(p<0,001)$. El grado de control de síntomas y nivel de severidad se asociaron con problemas de sueño: 25,3 (control total), 26,4 (controlada), 32,6 (parcialmente controlada) y 44,6 (no controlada); $p<0,001$ y 48,4 (grave), 39,0 (moderado), 32,6 (leve) y 26,5 (intermitente), $p<0,001$. En nuestro estudio, el género se asoció significativamente con la puntuación resumen del índice de sueño. 
Conclusión: La cantidad y calidad del sueño se asoció significativamente con el estado de salud de los pacientes asmáticos. Las guías deberían recomendar preguntar tanto por los síntomas de asma nocturno como asesorar a los clínicos acerca de hacer una historia global de sueño Un mejor control de la sintomatología nocturna del asma podría conllevar a una mejor calidad del sueño y una disminución en los síntomas relacionados con el sueño durante el día.

Palabras clave: Asma. Emplazamiento vida real. Calidad y cantidad de sueño. Escala de sueño MOS. Discapacidad.

\section{Introduction}

Current guidelines for the management of asthma recommend asking patients about nocturnal asthma symptoms [1]. However, because taking a full global sleep history from asthma patients is not advised [1-3], many clinicians are reluctant to ask about sleep problems and/or nocturnal sleep-related disturbances.

Although patients with asthma have disturbed sleep, there are relatively few data on the relationship between global sleep quality and quantity, asthma control, and daytime functioning, particularly in relation to routine clinical practice. The main goal of this study was to describe self-perceived sleep quality and quantity in asthma patients in a real-world setting according to different determinants of patient health status, including daytime functioning. This was a secondary objective of the CosteAsma study, which was primarily designed to determine the impact of asthma on indirect costs and productivity losses in Spain [4].

\section{Patients and Methods}

\section{Study Design and Patient Sampling}

The characteristics and design of the CosteAsma study have been described elsewhere [4]. In brief, Spanish allergists were invited to participate in a nationwide cross-sectional, multiwave, observational, epidemiological, multicenter study. A stratified multistage probability sample design without replacements was used to select the study participants, who were recruited from the health regions of the 17 autonomous communities of Spain. The study was approved by an institutional review board and the Spanish Ministry of Health.

\section{Selection of Patients}

Patients enrolled in the study had to meet the following inclusion criteria: 1) an age of 18 to 65 years; 2) a confirmed diagnosis of asthma based on lung function tests and the criteria set out in the Global Initiative for Asthma (GINA) guidelines [2] or the Spanish Guide to Asthma Management (GEMA) 2009 guidelines [3]; and 3) signed written informed consent. Excluded from participation were patients without a diagnosis of asthma in their medical record, patients with chronic obstructive pulmonary disease or any other condition precluding their participation or understanding of the study instructions, and patients who did not give their informed consent. All the data collected were provided by the participants at the study visit, with no additional information sought from other sources. All participants continued to receive their usual asthma treatment as indicated by their physician.

Because the study formed part of the CosteAsma study, we did not calculate sample size a priori. However, the number of adults in the study (>1000 individuals) was considered sufficient to achieve our objective.

\section{Data Collection and Measurements}

Data were obtained from evaluations by participating physicians (sociodemographic, clinical, and spirometry data) and patient-completed questionnaires. These included the Spanish versions of the Asthma Control Test (ACT) [5], the Sheehan Disability Scale (SDS) [6], and the Medical Outcomes Study (MOS) Sleep Scale $[7,8]$. It is recommended that the ACT should be taken at different times of the year. We classified degree of asthma control into 4 categories based on ACT scores [9]: uncontrolled asthma ( $\leq 15$ points), partly controlled asthma (16-19), controlled asthma (20-24), and fully controlled asthma ( 25 points).

Daytime functioning was assessed by the SDS, which is a simple questionnaire exploring patient level of disability. The score ranges from 0 (no disability) to 100 (total disability). Degree of disability was also grouped into 4 categories [10]: intermittent disability ( $\leq 10$ points), mild disability $(11-\leq 40)$, moderate disability $(41-\leq 60)$, and severe disability $(>60)$. Using a 10-point visual analog scale, respondents rate the extent to which their symptoms impair their 1) work, 2) social life or leisure activities, and 3) home life or family responsibilities.

The MOS-Sleep Scale is a 12-item self-administered scale designed to assess the quality and quantity of sleep. Quantity of sleep is scored as the average number of hours slept per night. Scores for the other domains and the 9-item composite sleep problem index (SLP-9) are transformed to a 0 to 100 scale, where higher scores indicate more of the attribute being assessed.

\section{Statistical Analysis}

Descriptive statistics were determined and normal distribution of data was tested using the Kolmogorov-Smirnov test or the Levene test. The $t$ test and 1-factor analysis of variance were used to assess statistical differences in quantitative measures meeting the assumptions necessary for the use of parametric tests, while the Mann-Whitney U test and the Kruskal-Wallis test were used when these assumptions were not met. The Pearson $\chi^{2}$ and Fisher exact test were used 
for $2 \times 2$ tables and the likelihood ratio test with $\mathrm{m} \times \mathrm{n}$ tables. A backward stepwise multivariate linear regression model was used to explore the associations between different variables (determinants) and the SLP-9 summary index. Determinants included, amongst others, daytime functioning and level of asthma control assessed, respectively, by the SDS and the ACT. General linear models with covariates were also used to analyze MOS-Sleep Scale scores (SLP-9 and individual domains) with patients grouped into categories according to ACT scores or level of asthma severity according to GINA/GEMA criteria. Multiple comparisons were adjusted by degrees of freedom using the Bonferroni procedure when applicable. Tests were carried out to determine compliance with the assumptions necessary for the use of parametric contrasts. Estimates were calculated with a 95\% CI in SPSS V17.0 [11].

Table 1. Demographic and Baseline Clinical Characteristics of Patients $(n=1098)$

\begin{tabular}{|c|c|}
\hline Age, mean (SD), y & $41.2(13.6)$ \\
\hline Women, $\mathrm{n}(\%)$ & $628(58.7)$ \\
\hline Body mass index, mean (SD), $\mathrm{kg} / \mathrm{m}^{2}$ & $25.6(4.0)$ \\
\hline \multicolumn{2}{|l|}{ Educational level, No. (\%) } \\
\hline No education & $44(4.1)$ \\
\hline Primary education & $314(29.3)$ \\
\hline Secondary education & $425(39.7)$ \\
\hline University education & $287(26.8)$ \\
\hline \multicolumn{2}{|l|}{ Work status, No. (\%) } \\
\hline Active & $360(33.3)$ \\
\hline Housewife & $157(14.5)$ \\
\hline Administrative assistant & $89(8.2)$ \\
\hline Teacher & $82(7.6)$ \\
\hline Retired & $13(1.2)$ \\
\hline Unemployed or studying & $94(8.7)$ \\
\hline Other & $287(26.5)$ \\
\hline \multicolumn{2}{|l|}{ Asthma severity, No. (\%) } \\
\hline Intermittent & $274(25.1)$ \\
\hline Mild & $294(26.9)$ \\
\hline Moderate & $299(27.4)$ \\
\hline Severe & $226(20.7)$ \\
\hline \multicolumn{2}{|c|}{$\begin{array}{l}\text { Asthma control by Asthma Control Test (ACT) } \\
\text { scale, No. }(\%)\end{array}$} \\
\hline Fully controlled (25) & $105(9.6)$ \\
\hline Controlled (20-24) & $360(32.8)$ \\
\hline Partly controlled (16-19) & $264(24.1)$ \\
\hline No controlled $(\leq 15)$ & $367(33.4)$ \\
\hline \multicolumn{2}{|l|}{ Causes of asthma, No. (\%) } \\
\hline Allergies & $820(75.2)$ \\
\hline Infections & $573(52.5)$ \\
\hline Exercise & $425(39.0)$ \\
\hline Humidity and cold weather & $390(35.7)$ \\
\hline Smoking & $337(30.9)$ \\
\hline Stress & $270(24.7)$ \\
\hline Other & $31(2.8)$ \\
\hline
\end{tabular}

\section{Results}

A total of 1186 adult asthmatic patients seen at least once between February and November 2010 were included by 102 allergists throughout Spain. Of these, 1098 (92.6\%) were eligible for inclusion in the statistical analyses; $58.7 \%$ were women and the mean (SD) age was 41.2 (13.6) years. The patients were evenly distributed regarding geographic location and seasonality (February-March, April-July, and August-September), with no relevant differences observed. According to ACT scores (Table 1), asthma was uncontrolled or partly controlled in $57.6 \%$ of patients, controlled in $32.8 \%$, and fully controlled in $9.6 \%$. Season, age, and severity of asthma symptoms as determined by GINA/GEMA criteria were not significantly associated with SLP-9 (data not shown). However, when the group was stratified by younger patients (18-40 years) versus older ones ( $>40$ years), significant, although moderate, differences were observed for SLP-9, with a higher summary index score observed in younger patients $(29.1 \mathrm{vs} 37.5, P<.05)$. Statistical significant differences were also observed for most of the MOS-Sleep Scale domains (Figure 1) when the group was stratified by sex, but when the group was stratified by smoking, the differences were significant in just 2 domains: quality of sleep $(P<.01)$ and awakening short of breath $(P<.05)$. Means were adjusted by age (years), sex, asthma severity (GINA/GEMA), and ACT score.

Severity of asthma based on GINA/GEMA criteria was significantly associated with a negative impact on sleep quality and quantity for the SLP-9 and all the MOS-Sleep Scale domains except snoring while sleeping, which showed a trend towards statistical significance (Table 2). In brief, the higher the severity of asthma, the higher the adjusted mean interference in scores. Of particular interest was the fact that patients with severe asthma slept on average 0.4 hours less than patients with intermittent asthma. After quantity of sleep, which had

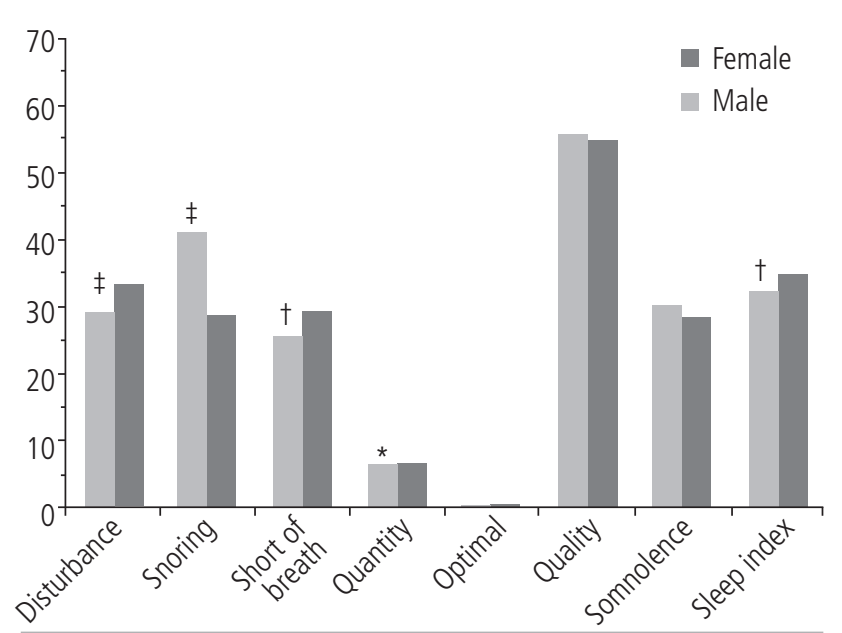

Figure. Mean scores for the different dimensions and the general sleep problem index of the Medical Outcomes Study Sleep Scale. Differences were significant at $\ddagger P<.001, \dagger P<.01 ;{ }^{*} P<.05$ vs female. Means are adjusted by age (years), asthma severity (Global Initiative for Asthma/ Spanish Guide to Asthma Management criteria), smoking, and Asthma Control Test scores. 
the highest $\mathrm{F}$ value (ie, this was the category that contributed most to the differences between severity groups), the SLP-9 and the sleep disturbance domain were most impacted by severity of asthma. As might be expected, quality of sleep decreased with increasing asthma severity (Table 2 ). Asthma severity according to ACT scores was also significantly associated with a negative impact in the SLP-9 and all the MOS-Sleep Scale domains (Table 3). Again, the worse the control, the higher the adjusted mean interference, without exception. In brief, patients with uncontrolled or partly controlled symptoms had higher scores in all domains of the MOS-Sleep Scale (Table 3). Sleep interference was also associated with level of disability as measured by the SDS (Table 4). Again, the higher the level of disability, the higher the adjusted mean interference in the domain and SLP-9 scores, without exception. In fact, there was a clear linear relationship between levels of disability and sleep disturbance across the board, with significant $(P<.001)$ and very high $\mathrm{F}$ values in all cases (Table 4). Educational level was also significantly associated with sleep disturbance; patients with no education had a significantly worse SLP-9 score as a result of poor scores in the sleep disturbance, snoring, and daytime sleepiness domains. Means were adjusted by age (years), sex, tobacco consumption, asthma severity (GINA/ GEMA), and ACT score.

The multivariate regression model applied to estimate the associations between various determinants and the SLP9 summary index showed a significant association for sex (Table 5). The fitted regression model, which included sex, educational level, occupational exposure to inhaled irritants, ACT score, and degree of disability (daytime functioning), perceived stress and familial support, as measured by the SDS, showed a moderate but significant adjusted $\mathrm{R}^{2}$ value $(0.511, P<.001)$. Occupational exposure to irritants and a low educational level had a lower impact on sleep problems

Table 2. Patient-Reported Sleep Disturbance According to the Different Dimensions and the General Sleep Problem Index of the Medical Outcomes Study (MOS) Sleep Scale by Level of Asthma Severity Based on GINA/GEMA Criteria ${ }^{a}$

\begin{tabular}{lcccccc}
\hline MOS Sleep Scale Dimension & $\begin{array}{c}\text { Intermittent } \\
(\mathrm{n}=262)\end{array}$ & $\begin{array}{c}\text { Mild Persistent } \\
(\mathrm{n}=279)\end{array}$ & $\begin{array}{c}\text { Moderate Persistent } \\
(\mathrm{n}=281)\end{array}$ & $\begin{array}{c}\text { Severe } \\
(\mathrm{n}=209)\end{array}$ & $\begin{array}{c}\text { F Value } P \text { Value } \\
\text { b }\end{array}$ \\
\hline Sleep disturbance (0-100) & $30.3(27.8-32.9)$ & $28.0(25.8-30.2)$ & $31.4(29.2-33.7)$ & $38.1(35.2,40.9)$ & 9.6 & $<.001$ \\
Snoring while sleeping (0-100) & $30.1(26.3-33.9)$ & $31.8(28.5-35.1)$ & $36.0(32.7-39.4)$ & $36.7(32.5,40.8)$ & 2.1 & .093 \\
Awakening short of breath (0-100) & $26.6(23.7-29.5)$ & $24.9(22.4-27.4)$ & $27.9(25.3-30.4)$ & $32.4(29.2,35.6)$ & 4.1 & .007 \\
Sleep quantity (0-24) & $6.8(6.7-7.0)$ & $7.0(6.8-7.1)$ & $6.6(6.5-6.7)$ & $6.4(6.2,6.5)$ & 10.9 & $<.001$ \\
Optimal sleep (0-1) & $0.58(0.51-0.64)$ & $0.62(0.57-0.68)$ & $0.51(0.46-0.57)$ & $0.46(0.39,0.50)$ & 4.5 & .004 \\
Sleep quality (0-100) & $56.7(53.4-60.1)$ & $59.0(56.1-61.9)$ & $53.4(50.5-56.4)$ & $49.8(46.1,53.5)$ & 4.7 & .003 \\
Daytime sleepiness (0-100) & $26.6(24.0-29.2)$ & $27.4(25.2-39.6)$ & $29.7(27.5-32.0)$ & $33.8(30.9,36.7)$ & 4.4 & .005 \\
Summary sleep problem index (0-100) & $33.0(31.2-34.8)$ & $31.4(29.9-33.0)$ & $33.3(31.8-34.9)$ & $38.4(36.5,40.4)$ & 9.9 & $<.001$
\end{tabular}

Abbreviations: GINA, Global Initiative for Asthma; GEMA, Spanish Guide to Asthma Management.

aData shown as mean values with $95 \% \mathrm{Cl}$.

${ }^{\mathrm{b}}$ Adjusted for age, sex, smoking, and Asthma Control Test score.

Table 3. Patient-Reported Sleep Disturbance According to the Different Dimensions and the General Sleep Problem Index of the Medical Outcomes Study (MOS) Sleep Scale by Level of Asthma Symptom Control Assessed Using Asthma Control Test Scores ${ }^{a}$

\begin{tabular}{lccccc}
\hline MOS Sleep Scale Dimension & $\begin{array}{c}\text { Uncontrolled } \\
(\mathrm{n}=367)\end{array}$ & $\begin{array}{c}\text { Partly controlled } \\
(\mathrm{n}=265)\end{array}$ & $\begin{array}{c}\text { Controlled } \\
(\mathrm{n}=360)\end{array}$ & $\begin{array}{c}\text { Fully Controlled } \\
(\mathrm{n}=105)\end{array}$ & $\begin{array}{c}\text { F Value } \\
(P \text { Value })\end{array}$ \\
\hline Sleep disturbance (0-100) & $45.4(42.1-47.7)$ & $30.3(28.1-32.6)$ & $22.8(19.9-24.2)$ & $20.7(17.0-24.4)$ & $65.1(<.001)$ \\
Snoring while sleeping (0-100) & $44,9(41.5-48.3)$ & $31.2(27.8-34.6)$ & $26.3(23.1-29,4)$ & $25.7(20.3-31.2)$ & $19.1(<.001)$ \\
Awakening short of breath (0-100) & $47.7(45.2-50.3)$ & $26.0(23.4-28.5)$ & $13.8(11.5-16.2)$ & $12.0(7.8-16.1)$ & $109.0(<.001)$ \\
Sleep quantity (0-24) & $6.2(6.1-6.3)$ & $6.8(6.7-6.9)$ & $7.0(6.9-7.1)$ & $6.8(6.5-7.0)$ & $21.8(<.001)$ \\
Optimal sleep (0-1) & $0.37(0.31-0.42)$ & $0.59(0.53-0.65)$ & $0.67(0.60-0.70)$ & $0.66(0.57-0.75)$ & $17.2(<.001)$ \\
Sleep quality (0-100) & $41.3(38.2-44.3)$ & $55.2(52.2-58.2)$ & $65.3(62.5-68.1)$ & $65.0(60.1-69.8)$ & $38.0(<.001)$ \\
Daytime sleepiness (0-100) & $38.3(35.9-40.6)$ & $26.9(24.6-29.2)$ & $23.5(21.3-25.6)$ & $23.5(19.7-27.2)$ & $26.1(<.001)$ \\
General index sleep problems (0-100) & $44.6(43.0-46.2)$ & $32.6(31.1-34.2)$ & $26.4(25.0-28.0)$ & $25.3(22.7-27.8)$ & $81.2(<.001)$
\end{tabular}

Data are shown as mean values with $95 \% \mathrm{Cl}$.

b $P$ values adjusted for age, sex, smoking, and asthma severity based on Global Initiative for Asthma and Spanish Guide to Asthma Management criteria. 
Table 4. Patient-Reported Sleep Disturbance According to the Different Dimensions and the General Sleep Problem Index of the Medical Outcomes Study (MOS) Sleep Scale by Level of Patient Disability Assessed Using Sheehan Disability Scale Scores ${ }^{a}$

\begin{tabular}{lccccc}
\hline MOS Sleep Scale Dimension & $\begin{array}{c}\text { Intermittent } \\
(\mathrm{n}=322)\end{array}$ & $\begin{array}{c}\text { Mild } \\
(\mathrm{n}=442)\end{array}$ & $\begin{array}{c}\text { Moderate } \\
(\mathrm{n}=184)\end{array}$ & $\begin{array}{c}\text { Severe } \\
(\mathrm{n}=135)\end{array}$ & $\begin{array}{c}\text { F Value } \\
(P \text { Value })\end{array}$ \\
\hline Sleep disturbance (0-100) & $22.8(20.6-25.1)$ & $30.5(28.9-32.2)$ & $38.9(36.2-41.6)$ & $47.2(43.6-50.8)$ & $36.1(<0.001)$ \\
Snoring while sleeping (0-100) & $27.2(23.7-30.8)$ & $33.0(30.4-35.6)$ & $38.3(33.9-42,6)$ & $44.9(39.1-50.6)$ & $7.2(<0.001)$ \\
Awakening short of breath (0-100) & $21.5(18.9-24.0)$ & $27.5(25.6-29.4)$ & $32.2(29.1-35.3)$ & $38.3(34.2-42.4)$ & $12.8(<0.001)$ \\
Sleep quantity (0-24) & $6.9(6.7-7.0)$ & $6.8(6.7-6.9)$ & $6.7(6.5-6.8)$ & $6.2(5.9-6.4)$ & $8.1(<0.001)$ \\
Optimal sleep (0-1) & $0.69(0.63-0.75)$ & $0.57(0.53-0.61)$ & $0.41(0.33-0.48)$ & $0.35(0.25-0.44)$ & $12.6(<0.001)$ \\
Sleep quality (0100) & $64.5(61.5-67.6)$ & $55.3(53.0-57.5)$ & $45.7(41.9-49.4)$ & $42.6(37.6-47.5)$ & $19.5(<0.001)$ \\
Daytime sleepiness (0-100) & $22.4(20.1-24.7)$ & $28.7(27.0-30.4)$ & $31.6(28.8-34.5)$ & $44.1(40.3-47.9)$ & $23.8(<0.001)$ \\
General index sleep problems (0-100) & $27.5(25.9-29.0)$ & $33.1(32.0-34.2)$ & $38.3(36.4-40.1)$ & $45.6(43.1-48.0)$ & $40.0(<0.001)$
\end{tabular}

aMean values with $95 \% \mathrm{Cl}$.

$P$ values adjusted for age, sex, smoking, Asthma Control Test score, and asthma severity asthma severity based on Global Initiative for Asthma and Spanish Guide to Asthma Management criteria.

in asthmatic adults, although these factors were statistically associated in the model. The main determinants, as indicated by their relative weights in the model, were mean disability score (SDS), ACT score, and patient-perceived stress.

\section{Discussion}

The association between asthma and sleep disorders, including risk of apnea, poor quality of sleep, and other sleep disturbances, has been documented by many studies [12-16]. However, while disturbed sleep is a complaint in patients with asthma, few studies have analyzed the relationship between global sleep quality and quantity, asthma control, and daytime patient functioning. We examined self-perceived sleep quality and quantity in patients with asthma in a real-world setting according to different health status determinants. Our findings show that several of these determinants were statistically associated with the summary MOS-Sleep Scale index, SLP-9. In other words, the patients' health status had a negative - and significant - impact on quantity and quality of sleep (adjusted $\left.\mathrm{R}^{2}=0.506, P<.001\right)$. Daytime functioning assessed by the SDS [6] had the greatest explanatory power $(\mathrm{t}=8.24)$ for the impact of daytime disability on sleep disturbance, with a $0.7 \%$ increase in level of disability ( 0.2 points on a scale of $0-30)$ producing a $1 \%$ increase in sleep disturbance. In other words, a $7 \%$ increase in disability was associated with a $10 \%$ impact on sleep disturbance. Level of asthma control (as assessed by the ACT) [5] was also a meaningful determinant $(\mathrm{t}=-8.18)$, with a 0.9 -point decrease in symptom control resulting in a $1 \%$ increase in sleep disturbance. Surprisingly, asthma severity was not a determinant of sleep disturbance in the regression model, despite the association observed in the univariate analysis. In other words, achieving control of asthma symptoms would appear to positively impact sleep quality and quantity, regardless of the severity of disease. Possible explanations are that patients with poorly controlled asthma take longer to fall asleep [17] or that adult asthmatic patients have slightly lower sleep efficiency and more nocturnal awakenings $[13,14]$.
Table 5. Determinants Associated With the General Sleep Problem Index of the Medical Outcomes Study Sleep Scale in Patients With Asthma ${ }^{a}$

\begin{tabular}{lccc}
\hline Variable & ß Coefficient (SE) & Sig. & $\mathrm{t}$ \\
\hline Sex & $1.99(0.72)$ & 0.006 & 2.75 \\
$\begin{array}{l}\text { Educational level } \\
\begin{array}{l}\text { Occupational } \\
\text { exposure to irritants }\end{array}\end{array}$ & $-1.33(0.44)$ & 0.003 & -3.01 \\
$\begin{array}{l}\text { Asthma Control } \\
\text { Test score }\end{array}$ & $-0.89(0.11)$ & $<0.001$ & -8.18 \\
$\begin{array}{l}\text { Disability score (SDS) } \\
\text { Familial support }\end{array}$ & $0.21(0.03)$ & $<0.001$ & 8.24 \\
$\begin{array}{l}\text { (SDS, item \#4) } \\
\text { Perceived stress }\end{array}$ & $-0.04(0.01)$ & $<0.001$ & -3.56 \\
(SDS, item \#5) & $0.10(0.02)$ & $<0.001$ & 5.01 \\
\hline
\end{tabular}

Abbreviation: SDS, Sheehan Disability Score.

${ }^{\text {a Adjusted }} \mathrm{R}^{2}=0.511, P<.001$.

In our study, sex was significantly associated with the SLP-9, and surprisingly, scores for snoring were higher in women than in men. Snoring is a sleep-related breathing disorder that affects at least $20 \%$ of the population and around $50 \%$ of men aged 50 years old [16]. In asthma patients, it could be caused by an increase in upper airway suction pressures during active asthma, or by upper airway inflammation. Asthma may also be activated by snoring-induced gastroesophageal reflux [17]. Familial support was inversely associated with sleep impairment, suggesting that patients who receive more help from their families sleep better. Perceived stress, however, was associated with impaired sleep, with greater disturbance observed in those with higher levels of self-reported stress. Educational level was also significantly associated with sleep disturbance, with greater impairment observed in patients with lower levels of education. This might be the consequence of poorer management of aerosol delivery devices, possibly related to a lack of adequate education or difficulties in 
understanding the management of drug delivery in asthma, as has been previously observed [18-19]. Our observation of significantly lower ACT scores in patients without studies or with just primary education would appear to support this theory. Finally, exposure to irritants was retained in the logistic regression model because it was considered a confounding variable since no significant differences were observed for the SLP-9 or any of the MOS-Sleep Scale domains (data not shown).

We also found that smoking had a negative, albeit weakly significant, influence on sleep quality and quantity, and also that smokers experienced greater shortness of breath on awakening than nonsmokers. Smoking has been found to increase the risk of airway obstruction in adults who develop asthma after the age of 10 years [20]. This finding is relevant, since smoking is one of the risk factors that influence therapeutic response to corticosteroids, and is thus related to poor asthma control [21].

The results of our study on the quality and quantity of sleep in asthmatic adults using a self-administered questionnaire are of relevance considering the few studies on this subject in the literature. We found just 2 studies that have used the MOS-Sleep Scale in asthmatic patients; one was a national survey of allergic rhinitis in a French adult populationbased study [22] and the other was a part of a clinical trial comparing budesonide and formoterol in patients with moderate to severe asthma [23]. The MOS-Sleep Scale is a simple self-administered questionnaire that can be used at primary care level without overloading either physicians or nurses. Despite its simplicity, however, it can provide very important information. Obviously, data on sleep disturbance assessed using a self-reported scale may be less reliable than polysomnography data. Although polysomnography is the gold standard for assessing sleep disturbances, it is also a costly method and its use in questionnaire-based population studies, such as ours, may be limited. Furthermore, polysomnography and other instrument-based methods for exploring sleep status are not always feasible in routine clinical practice, and hence simple-to-administer methods such as the MOS-sleep scale can be of help in certain cases.

Although we enrolled a large sample of patients with asthma from across Spain and during different seasons of the year, thus, capturing the possible impact of seasonality on symptom control and/or patient functioning, our study does have some limitations. For example, we did not analyze comorbidities, several of which, such as obesity, rhinitis, and gastroesophageal reflux, may have effects on sleep and sleepiness, as is also the case with certain drugs used to treat comorbid conditions. Another possible limitation is that we explored daytime functioning using the SDS, which apart from being a self-administered questionnaire may be considered too simple to capture patient functioning as a whole. However, this scale has provided researchers with a simple tool to analyze how health status can impact daily functional activity in patients with different health conditions [24].

Despite its possible limitations, this large cross-sectional, observational, seasonal, multiwave survey study found a relationship between sleep quality and quantity and degree of asthma control, which, in addition to sex, educational level, smoking status, and impaired daytime functioning, was a significant determinant of sleep disturbance in adult asthmatics.
Better control of nocturnal asthma symptoms could lead to improved sleep quality and a decrease in daytime sleep-related symptoms and, perhaps disability.

\section{Funding}

This study was funded by Pfizer, S.L.U.. Pedro Ojeda was not financially compensated for his participation in the development of this manuscript.

\section{Conflicts of Interest}

Verónica Sanz de Burgoa and Javier Rejas are employees of Pfizer. The authors declare no other conflicts of interest in relation to this study.

\section{References}

1. U.S. National Institutes of Health. Guidelines for the diagnosis and management of asthma: Expert Panel Report 2. Department of Health and Human Services; 1997.

2. GINA.org [Internet] Global Initiative for Asthma. Global strategy for asthma management and prevention. Updated 2011. Available from: http://www.ginaasthma.org (Accessed March 2015).

3. GEMA.com [Internet]. GEMA 2009. Guía Española para e manejo del asma. Área de Asma de SEPAR. Available from: http://www.gema.com (Accessed March 2015).

4. Ojeda P, Sanz de Burgoa V J. Costs associated with workdays lost and utilization of health care resources because of asthma in daily clinical practice in Spain. Investig Allergol Clin Immunol. 2013;23: 234-41.

5. Nathan RA, Sorkness CA, Kosinski M, Schatz M, Li JT, Marcus P, Murray JJ, Pendergraft TB. Development of the asthma control test: a survey for assessing asthma control. J Allergy Clin Immunol. 2004;113: 59-65.

6. Sheehan DV, Harnett-Sheehan K, Raj BA. The measurement of disability. Intl Clin Psychopharmacology. 1996;11 (Suppl 3): 89-95

7. Hays RD, Martin SA, Sesti AM, Spritzer KL. Psychometric properties of the Medical Outcomes Study Sleep measure. Sleep Med Rev. 2005;6: 41-4.

8. Hays RD, Stewart AL. Sleep measures. In: Stewart AL and

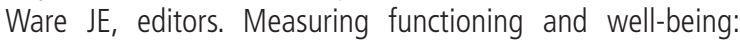
The Medical Outcomes Study approach. Durham, NC: Duke University Pres;1992. p. 235-59.

9. Terzano C, Cremonesi G, Girbino G, Ingrassia E, Marsico S, Nicolini G, Allegra L;PRISMA (PRospectlve Study on asthMA control) Study Group. PRISMA 1-year prospective real life monitoring of asthma control and quality of life in Italy. Respir Res. 2012;13:112. doi: 10.1186/1465-9921-13-112.

10. Klinkman MS. Assessing functional outcomes in clinical practice. Am J Manag Care. 2009;15(11 Suppl): S335-42.

11. IBM SPSS Statistics v. 17.0.

12. Teodorescu M, Polomis DA, Gangnon RE, Consens $F B$, Chervin RD, Teodorescu MC. Sleep duration, asthma and obesity. J Asthma. 2013;50:945-53. doi: 10.3109/02770903.2013.831871.

13. Teodorescu M, Polomis DA, Gangnon RE, Fedie JE, Consens FB, Chervin RD, Teodorescu MC. Asthma Control 
and Its Relationship with Obstructive Sleep Apnea (OSA) in Older Adults. Sleep Disord. 2013;2013:251567. doi: 10.1155/2013/251567.

14. Khan WH, Mohsenin V, D'Ambrosio CM. Sleep in asthma. Clin Chest Med. 2014;35:483-93. doi: 10.1016/j.ccm.2014.06.004.

15. Böing $S$, Randerath WJ. Sleep disorders in asthma and chronic obstructive pulmonary disease (COPD). Ther Umsch. 2014;71:301-8. doi: 10.1024/0040-5930/a000517.

16. Ekici A, Ekici M, Kurtipek E, Keles H, Kara T, Tunckol M, Kocyigit P. Association of asthma-related symptoms with snoring and apnea and effect on Health-Related Quality of Life. CHEST. 2005; 128:335.

17. Krouse HJ, Yarandi H, McIntosh J, Cowen C, Selim V. Assessing sleep quality and daytime wakefulness in asthma using wrist actigraphy. J Asthma. 2008;45:389-95.

18. Basheti IA, Qunaibi E, Bosnic-Anticevich SZ, Armour CL, Khater S, Omar M, Reddel HK. User error with Diskus and Turbuhaler by asthma patients and pharmacists in Jordan and Australia. Respir Care. 2011;56:1916-23.

19. Myers TR, Bollig SM, Hess DR. Respiratory care year in review 2012: Asthma and sleep-disordered breathing. Respir Care. 2013; 58:874-83. doi: 10.4187/respcare.02481.

20. Aanerud $M$, Carsin $A E$, Sunyer J, Dratva J, Gislason T, Jarvis D, deMarco R, Raherison C, Wjst M, Dharmage SC, Svanes C. Interaction between asthma and smoking increases the risk of adult airway obstruction. Eur Respir J. 2015;45:635-43. doi: 10.1183/09031936.00055514.

21. Divya Reddy and Frederic F. Little. Glucocorticoid-resistant asthma: more than meets the eye. J Asthma. 2013;50: 1036-44.
22. Klossek JM, Annesi-Maesano I, Pribil C, Didier A. INSTANT: national survey of allergic rhinitis in a French adult population based-sample. Presse Med. 2009;38:1220-9. doi: 10.1016/j. Ipm.2009.05.012.

23. Chervinsky P, Baker J, Bensch G, Parasuraman B, Boggs R, Martin P, O'Dowd L. Patient-reported outcomes in adults with moderate to severe asthma after use of budesonide and formoterol administered via 1 pressurized metered-dose inhaler. Ann Allergy Asthma Immunol. 2008;101:463-73. doi: 10.1016/S1081-1206(10)60284-0.

24. Klinkman MS. Assessing functional outcomes in clinical practice. Am J Manag Care. 2009;15(11 Suppl):S335-42.

\footnotetext{
- Manuscript received May 29, 2015; accepted for publication December 18, 2015.
}

\section{Verónica Sanz de Burgoa}

Medical Department, Pfizer S.L.U

Avda. Europa 20-B

28108 Alcobendas (Madrid), Spain

E-mail: verónica.sanz.de.burgoa@pfizer.com 